\title{
Statistical study of the influence of the data sampling interval on the estimation of wind turbine energy
}

\author{
Dhaker Abbes*, André Martinez*, Gérard Champenois**, Jean Paul Gaubert** \\ * EIGSI, 26 rue de vaux de Foletier, 17041 La Rochelle Cedex France Dhaker.abbes@eigsi.fr \\ ** LAII- ESIP Bât de Mécanique 40, Avenue du Recteur Pineau 86022 Poitiers Cedex France
}

\begin{abstract}
Main deficiency for wind power is variability. It is really difficult to predetermine the wind's potential since wind velocity cannot be controlled or predicted with pinpoint accuracy.

In this paper, two different methods are applied in order to estimate the monthly wind energy for different sites; those estimations are done using Weibull distribution and calculating energy with direct integration methodology.
\end{abstract}

In additional, the influence of the data sampling interval is studied. Results show that the computational method based on the integration of the power is more accurate. Also, it is shown that the hourly time resolution provides satisfactory accuracy in wind resource estimation, in comparison with one minute's resolution.

Results allow better design of wind or hybrid systems. Moreover, wind speed acquisitions are minimized. A shorter time of treatment and less expensive measurement equipments are required.

Keywords- wind power, wind modelling, energy estimation, weibull distribution, computational method, data sampling interval.

\section{INTRODUCTION}

Energy power from renewable sources, especially wind turbine generators, is being considered as an important generation alternative in the electrical power systems around the world due to their non contaminant nature and low environmental effects [1]. During the last decade, there has been a tremendous growth, both in size and power of wind energy converters. [2]

However, it is difficult to predetermine the potential of the wind due to a large number of "disruptive" parameters, (wind gusts, wind direction, etc.) [3]. In fact, wind power's main deficiency as a power source is variability. Since wind velocity cannot be controlled or predicted with pinpoint accuracy, alternatives must be available to meet demand fluctuations. [4]

In this context, energy output estimation for wind turbines has been dealt by a number of researchers and references. Some authors implement simple methods evaluating a perturbation from mean wind speed and variance.For example, to calculate the available wind power, Kainkwa [5] suggests a formula,

$P a=\frac{1}{2} \rho\left[\bar{V}^{3}+3 \bar{V} \sigma^{2}\right]$

Where $\rho$ is the air density, $\bar{V}$ represents mean wind speed and $\sigma^{2}$ the variance of wind speed. As well, Paul Gipe [6] introduced the "swept area's' method. It consists of determining the wind power and then estimating the potential production of energy Ea, simply knowing the area swept by the rotor A:

$$
E a=8760 h / \text { year } * 1 k w / 1000 W *\left[\frac{1}{2} \rho A \bar{V}^{3} F \eta\right],
$$

With $F$ is the the Rayleigh distribution factor and $\eta$ is the overall efficiency of the wind conversion system.

Although, theses methods are direct and simple, it does not take into account all critical factors that affect the amount of wind energy. Therefore, they can only partially report the regional peculiarities of the site. So, these methods can give just an approximate estimation of wind turbine energy and not a precise estimation.

Other researches focus on more "complicated" methods based on wind speed distribution models especially the twoparameter Weibull distribution. In fact, Adam Simon-Muela and all [3] have described a technique to estimate the wind energy production using Weibull distribution. This technique 
has yielded good results. Also, they intended to provide a forecast of wind turbine energy production from several experimental measurements carefully correlated with available wind speed data. Unfortunately, results were not fully satisfactory.

In the same context, Luminita Barote and Lonela NEGREA [7] have developed an algorithm to calculate the probability of wind energy using the Weibull distribution.

In this paper, we have estimated the production of three different wind farm sites with a satisfactory accuracy. Moreover, we have analyzed the influence of wind speed resolution on the estimation of wind turbine energy. Subsequently, we will present some notions about wind power, and then explicit methods and results.

\section{WIND POWER:}

The wind is a motion of air mass. If air mass is $\mathrm{m}$ and it moves with an average velocity $\mathrm{V}$, the kinetic energy (KE) of wind is:

$$
\mathrm{KE}=1 / 2 \mathrm{~m} \mathrm{~V}^{2}
$$

Consider the wind passing perpendicularly (normally) through an area A. If the air flow is smooth, free from eddies, and has a density (mass per unit volume) of $\rho$, then, the power in the wind is:

$$
P w=1 / 2 \rho \mathrm{AV}^{3}
$$

Equation (2) is the basis of all wind power and energy calculations. The most significant feature is that the wind power is proportional to the average velocity cubed. It is obvious that wind speed is therefore the dominant consideration in wind machine location.

The air density $\rho$ varies with altitude and with atmospheric conditions such as temperature, pressure and humidity.

In the USA a commonly quoted figure is:

$$
\rho=1.275 \mathrm{Kg} / \mathrm{m}^{3}
$$

At sea level, under dry conditions at a temperature $0^{\circ} \mathrm{C}$. Only a fraction of the total theoretical power available in the wind, (2), is extractable. According to Betz' law,

$$
\begin{aligned}
& P \text { ex, max }=\frac{8}{27} \rho A V^{3}=\left(\frac{16}{27}\right) \frac{1}{2} \rho A V^{3} \\
& P \text { ex, } \max =(0.593) \frac{1}{2} \rho A V^{3}
\end{aligned}
$$

The power actually available to drive a practical wind machine is much less than the theoretical maximum value defined in (5).

A practical wind machine, often called a wind turbine, experiences air drag on the blades and friction of the air on the blades causing heat losses. In addition, the rotation of the rotor causes swirling of the air, which reduces the torque imparted to the blades. The net effect of the various losses is incorporated into a parameter called the power coefficient $\mathrm{Cp}$. With an up stream air velocity $\mathrm{V}$, the extractable power can be written as:

$P \operatorname{ex}=C p \frac{1}{2} \rho A V^{3}$

Where parameter $\mathrm{Cp}$ is a dimensionless variable but for practical wind turbines its value is usually in the range $0 \leq c p \leq 0.4$.

If we consider a small wind converter system, up to a few $\mathrm{kW}$ rating, the overall efficiency $\eta$ is of the order 20-25\% [8].

The electrical output power may be written as:

$$
P \mathrm{e}=C p \cdot \eta g b \cdot \eta g \cdot P w=C p \cdot \eta g b \cdot \eta g \cdot \frac{1}{2} \cdot \rho A V^{3}
$$

With:

$$
\begin{gathered}
C p=\frac{P e x}{P w}=\text { turbine efficiency } \\
\eta g b=\frac{P g}{P e x}=\text { gearbox efficiency } \\
\eta g=\frac{P e}{P g}=\text { generator efficiency }
\end{gathered}
$$

In the present article, the wind energy calculations were carried out for a wind turbine with $9 \mathrm{~m}^{2}$ swept area and using an overall efficiency factor $\eta=25 \%$.

\section{WIND ENERGY ASSESSMENT}

\section{A. Wind speed measurement for selected locations}

Data for our study was obtained from an American Web site [9]. They correspond to three different locations:

a) National Wind Technology Center- Colorado (Latitude: $39^{\circ}$ North, Longitude: $105^{\circ}$ West, Elevation: 1855 meters):

Data were captured using a wind sensor that is measured using a Campbell Scientific SDM-INT8 interval timer, which 
samples the sensors at a high frequency (up to 1 microsecond) and reports the average value every $1 \mathrm{~min}$ to the data logger.

b) University of Nevada- Las Vegas (Latitude: $36.06^{\circ}$ North, Longitude: $115.08^{\circ}$ West, Elevation: 615 meters):

Data were measured by an RM Young 4-blade propeller and attached vane mounted on a pole at approximately $9 \mathrm{~m} \mathrm{(30}$ feet) above ground. Registration is made every 1-minute interval.

c) Xcel Energy Comanche Station - Pueblo, Colorado (Latitude: $38.2098^{\circ}$ North, Longitude: $104.5724^{\circ}$ West, Elevation: 1490 meters):

Data were measured by an RM Young 3-cup anemometer and vane mounted 10 meters above ground level on tower. Registration is made every 1-minute interval.

\section{B. Energy estimation by Weibull distribution}

Different wind speed distribution models are used to fit the wind speed distribution over a time period, such as the Weibull, the Rayleigh and the Lognormal [10]. However, in recent years, most attention has been focused on the Weibull distribution for wind energy applications [11].

The Weibull probability density function has the following form:

$$
f(v)=\frac{k}{c}\left(\frac{v}{c}\right)^{k-1} \exp \left[-\left(\frac{v}{c}\right)^{k}\right]
$$

The corresponding cumulative distribution function is:

$$
F(v)=1-\exp \left[-\left(\frac{v}{c}\right)^{k}\right] ;(k>0, v>0, c>0)
$$

Where $\mathrm{v}$ is wind speed and $\mathrm{c}$ and $\mathrm{k}$ are two parameters, called the scale and shape parameters, respectively [12] [13].

In this paper and from available wind data, we have estimated the two-parameters of Weibull distribution for every site and every month by using Matlab software and by applying the regression method:

The cumulative distribution function, equation (9), can be linearized as follows [13]:

$$
\ln [-\ln [1-F(V)]=k \ln (V)-k \ln (c)
$$

So we obtain a straight line equation:

$y=a x+b$

Where $\mathrm{x}$ and $\mathrm{y}$ are the variables, $\mathrm{a}$ is the slope and $\mathrm{b}$ is the intercept of the line on the y-axis. $y=\ln [-\ln (\ln (1-F(v))]$

$a=k$

$x=\ln (v)$ And

$b=-k \ln (c)$

The parameters in the resulting equation are obtained using the least squares method. The scale and shape parameter estimators are $\hat{k}=a$ and $\hat{c}=\exp (-b / \hat{k})$.

To determine the energy capture of the turbine over a time period $\mathrm{T}$, we can just multiply the power Pe by $\mathrm{f}(\mathrm{V}) * \mathrm{~T}$ so that the energy captured over a time period $\mathrm{T}$ (ignoring down time) will be:

$$
E=\int_{V i}^{V o} P e(V) * f(V) d V
$$

With $\mathrm{Vi}$ is the wind cut in speed (4m/s [14] [8]) and Vo is the cut out wind speed (25 m/s [14] [15]).

Unfortunately, the integral does not have a closed mathematical form in general and so a numerical integration is required, such as the trapezoidal rule or Simpson's rule [14] [16].

Within one year time period and for 10 data wind points, the energy capture will be, using the trapezoidal rule,

$E=365 * 24 * \sum_{i=1}^{9}\left(\left(P_{e}(V i+1) f(V i+1)+P e(V i) f(V i)\right)(V i+1-V i)\right) / 2$

Obtained results appear in the histograms of figures (1, 2 and 3). They confirm the annual and inter-annual variability of wind energy. For example, in the National Technology CenterColorado, January 2006 was very windy comparing with the other months.

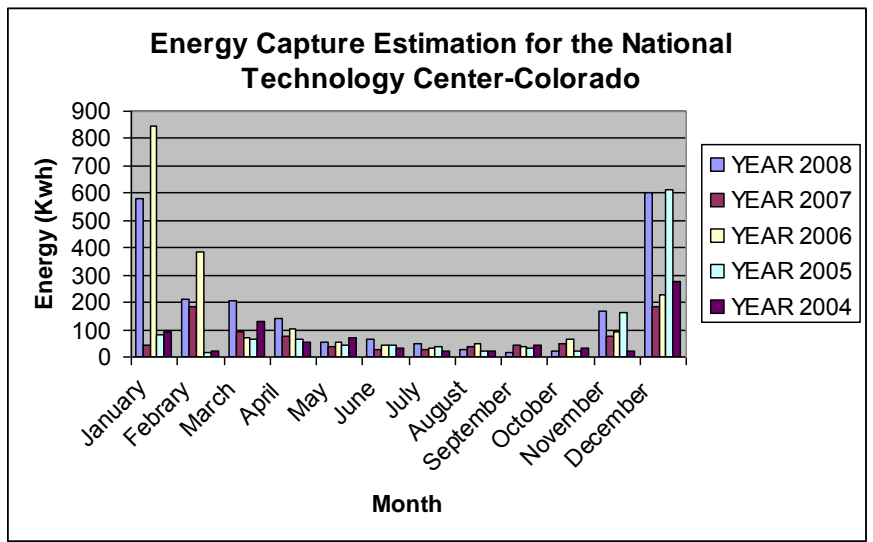

Figure 1: Energy Capture Estimation for the National Technology Center - Colorado using weibull distribution 


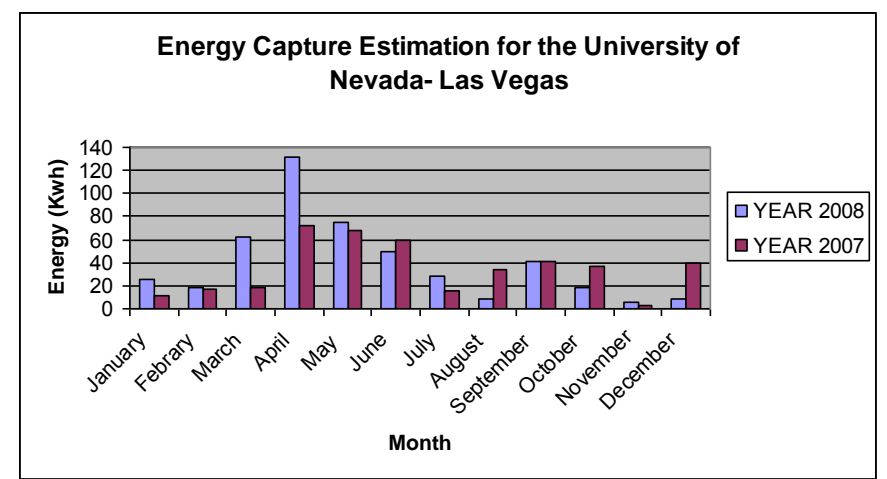

Figure 2: Energy Capture Estimation for the University of Nevada - Las Vegas using weibull distribution

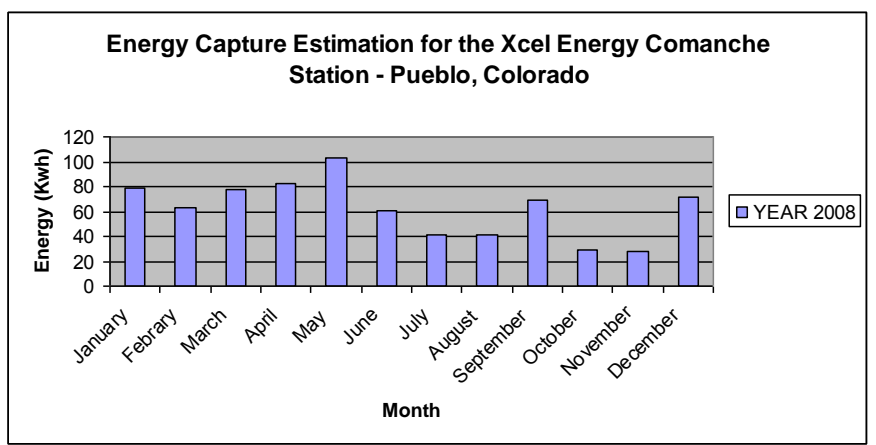

Figure 3: Energy Capture Estimation for the Xcel Energy Comanche Station- Pueblo, Colorado using weibull distribution

Eestimation of wind energy depends on the goodness of weibull distribution fitting and consequently in the estimation of weibull parameters. The goodness of fit can be evaluated knowing: - Summed Square of residuals (SSE), - the square of the correlation between the response values and the predicted response values (R-square), - Degrees of freedom (Adjusted R-square) and - the Root Mean Squared Error (RMSE).

As an example, for January 2007 of the National technology center - Colorado, we have as parameters of goodness of fit:

SSE: 0.04532

R-square: 0.9596

Adjusted R-square: 0.9595

RMSE: 0.01352

Although these figures indicate a global good fit (SSE and RMSE close to zero, R-square and Adjudsted R-square close to one), the probability plot (figure 4) shows that the adjusted Weibull distribution is not adequate to model wind data of this month especially for wind speeds between $4 \mathrm{~m} / \mathrm{s}$ and 25 $\mathrm{m} / \mathrm{s}$ :

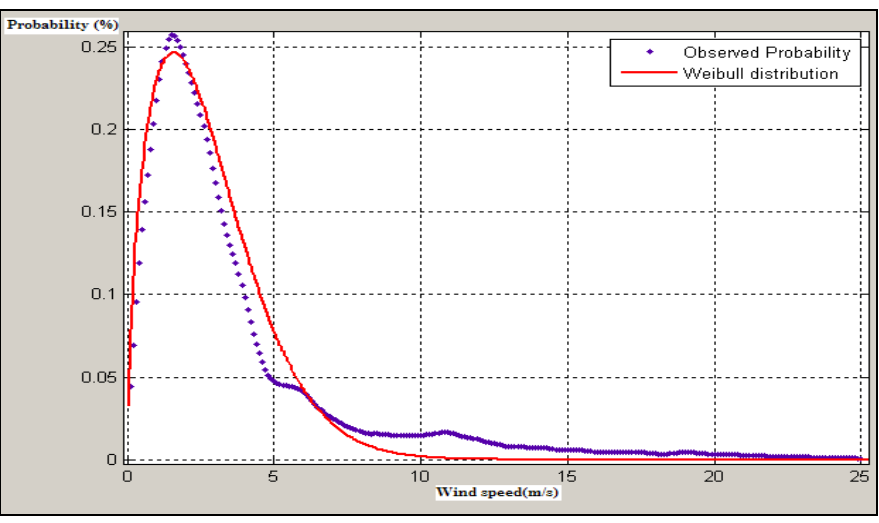

Figure 4: Probability plot and Weibull distribution curve fitting of wind data January 2007- National Technology Center-Colorado

This ascertainment is confirmed by calculating the coefficient of determination R-Square for wind speeds between $4 \mathrm{~m} / \mathrm{s}$ and $25 \mathrm{~m} / \mathrm{s}$ :

$$
R-S q u a r e=1-\frac{\sum_{i}(f \operatorname{mes}(v)-f e s t(v))^{2}}{\sum_{i}(f \operatorname{mes}(v)-\operatorname{mean}(f \operatorname{mes}(v)))^{2}}
$$

$f m e s(V)$ and $f e s t(v)$ corresponds respectively to observed and modelled probability values.

We find: $R 2=0.5665$.

So, the fit of weibull distribution of wind speed data is not always a good approximation. Consequently, utilizing the weibull parameters to estimate wind energy may give biased values.

Our analysis of Weibull parameters shows that:

- For the National Wind Technology Center -Colorado the shape parameter $\mathrm{k}$ varies between 1.155 and 2.127 while the scale parameter $\mathrm{C}$ varies between 2.7878 and 7.1118.

- For the University of Nevada -Las Vegas the shape parameter $\mathrm{k}$ varies between 1.007 and 1.713 while the scale parameter $\mathrm{C}$ varies between 1.426 and 3.7787 .

- For Xcel Energy Comanche Station - Pueblo, Colorado the shape parameter $\mathrm{k}$ varies between 1.543 and 2.153 while the scale parameter $\mathrm{C}$ varies between 2.9916 and 4.322 .

The scale factor ' $c$ ' is closely related to the mean wind speed and the shape parameter ' $\mathrm{k}$ ' is inversely related to speeds' variance about the average value .i.e. high value of ' $\mathrm{k}$ ' means low variance and low value of ' $\mathrm{k}$ ' means high variance $\left(\sigma^{2}\right)$. It should be noted from Weibull parameter analysis that there is a wide variation in the parameters estimation over months. 
This suggests very different distribution patterns of wind speed over months at selected stations.

\section{Energy Estimation using computational method (Numerical integration of the power)}

Produced energy can be estimated by numerical integration of the wind power Pe. Several methods of numerical integration such as the trapezoidal method or also the method of Simpson can be implemented at this stage.

In this paper, we have developed a program to draw the power curve. Graphically, the energy output can be given by the area under this curve. This area is calculated using the trapezoidal method with the function Energy = trapz (Time, Power):

$E($ estim $)=\frac{1}{3600} \sum_{i=1}^{744 * 24 * 60} \frac{1}{2}(P e(V i)+P e(V i+1)) .60(16)$

Results are shown on figures 4 to 6 for different sites:

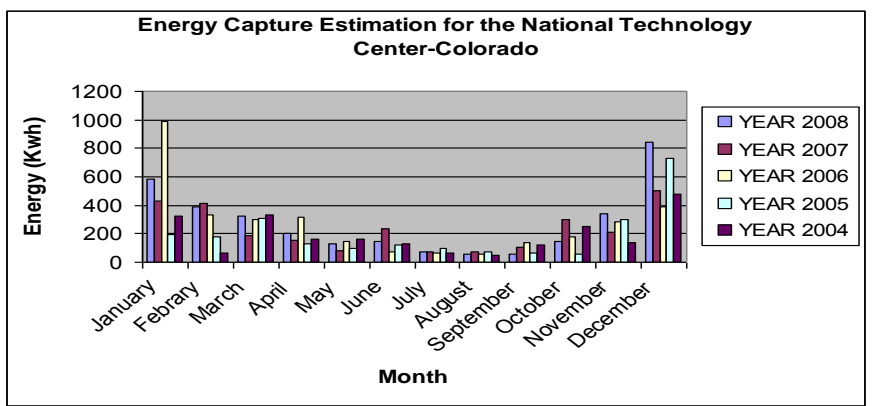

Figure 4: Energy Capture Estimation for the National Technology Center - Colorado using computational method

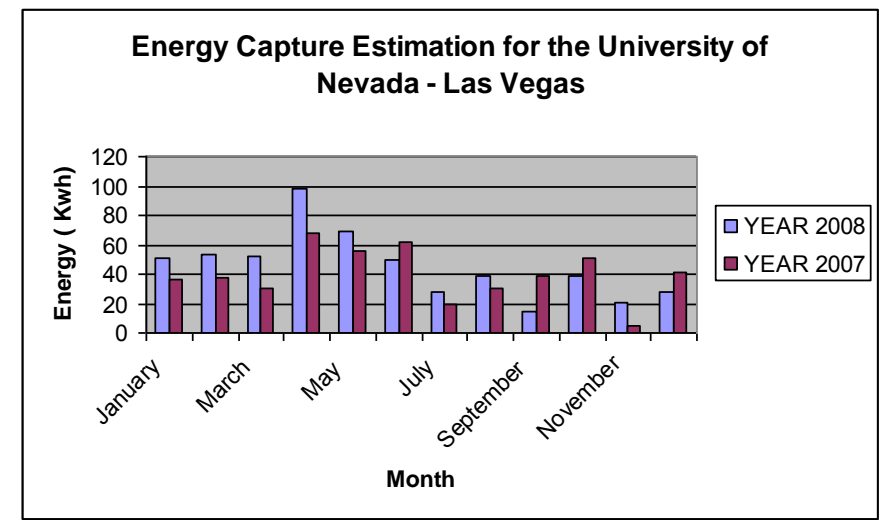

Figure 5: Energy Capture Estimation for the University of Nevada - Las Vegas using computational method
Energy Capture Estimation for the Xcel Energy Comanche Station -Pueblo,Colorado

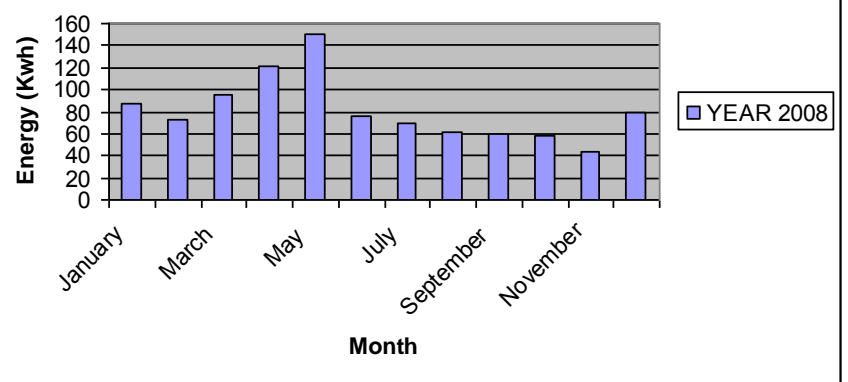

Figure 6: Energy Capture Estimation for the Xcel Energy Comanche Station- Pueblo, Colorado using computational method

In that context, results shows that weibull distribution use doesn't estimate wind energy output accurately. A significant difference between calculations made with weibull distribution and direct integration of the power is underlined.

The method of integrating the power versus time is easier to implement. It takes into account almost all the factors of the site (gusts, changes in wind direction, etc...) as it can use a huge data of wind speed. The calculation of energy by integrating the power takes its justification from the definition of the energy itself. That validates the use of this method for a precise estimation of wind generation. It gives more accurate estimations than method using weibull distribution because in its case we don't have to estimate any parameter. It is almost a direct calculation.

\section{STATISTICAL STUDY OF THE INFLUENCE OF THE DATA SAMPLING INTERVAL IN THE ESTIMATION OF WIND ENERGY CAPTURE}

\section{A. Principle}

Using the available data of wind speed, we made the estimation of energy using different time steps between one minute and two hours. We supervised the influence of sampling intervals on the accuracy of the estimation. The study has been made twice: initially directly with the data available and in a second time with filtered data respecting Shannon. Filtering is made by a Butterworth structure. The filter frequency is adjusted to be half of the sampling frequency. 


\section{B. Results and discussion}

The results indicate that-for the different sites and for all months- there is no significant difference between energy values obtained with a sampling interval one minute and those obtained with sixty minutes (difference less than $10 \%$ ). The hourly time resolution, compared to one minute resolution provides satisfactory accuracy in wind energy estimation. Consequently, it is sufficient to just take a sample every hour in a month to get a good estimation of the production of a wind turbine. However, the values of estimated energy vary randomly with the sampling interval.

By comparison, if we filter the data of wind speed while respecting Shannon using a Butterworth filter, we note that the energy decreases when the vesting period of the wind increases. Also, a loss of energy (maximum $10 \%$ ) at one minute using filtered data comparing to unfiltered data at the same resolution was detected. Besides, using filtered data, for sampling intervals between one minute and thirty minutes, the energy decreases linearly (figure 7).

As an illustration, table 1 presents all results for the National Wind Technology Center- Colorado in January 2008:

\begin{tabular}{|l|l|l|l|l|}
\hline \multicolumn{5}{|c|}{ YEAR 2008 ( National Wind Technology Center- } \\
Colorado)
\end{tabular}

Table 1: Energy capture estimation for the month of January 2008 (National Wind Technology Center-Colorado) using filtered and no filtered wind speed Data

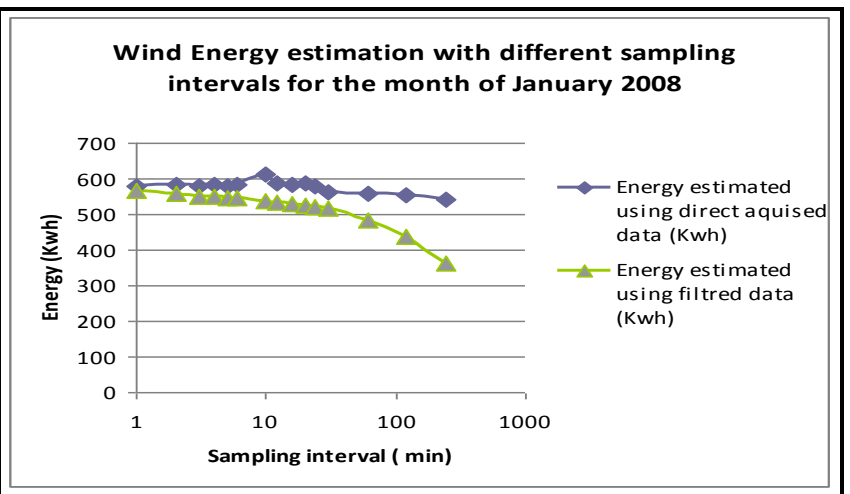

Figure 7: Wind Energy estimation with different sampling intervals for the month of January 2008 (National Wind Technology Center-Colorado) using filtered and no filtered wind speed Data

Results can be explained by the fact that for high frequencies (between $(1 / 60) \mathrm{Hz}$ and $(1 / 3600) \mathrm{Hz}$ ), the wind speed, a random variable, has the same behaviour as a white noise Besides, for periods of acquisition of wind between $60 \mathrm{~s}$ and $3600 \mathrm{~s}$, the statistical characteristics of the data (max, min, mean, variance, etc.) are almost invariant. Indeed, as an example for wind data of January 2008 (National Wind Technology Canter-Colorado):

- Using one minute sampled Data, we have:

Mean $=5.45 \mathrm{~m} / \mathrm{s}$, Variance $=18.52, \min =0.32 \mathrm{~m} / \mathrm{s}$ and $\max =25.46 \mathrm{~m} / \mathrm{s}$,

- Using hourly sampled Data, we have:

Mean $=5.43 \mathrm{~m} / \mathrm{s}$, Variance $=17.92$, Min $=0.32 \mathrm{~m} / \mathrm{s}$ and $\operatorname{Max}=23.53 \mathrm{~m} / \mathrm{s}$.

\section{Conclusion}

Estimation of wind energy output for small-scale systems is the focus of our paper. We have also studied the influence of the sampling interval on the wind energy estimation accuracy. To achieve this objective, we have applied two different methods for estimating the monthly output in three different American sites.

Investigations have showed that:

- The computational method based on integrating power versus time is more accurate.

- There is a very different distribution pattern of wind speed over months at selected stations.

- If wind speed data with an average one minute value is used, estimated energy varies randomly with sampling interval. 
- The hourly time resolution, compared to one minute resolution provides satisfactory accuracy in wind energy estimation.

- It is sufficient to choose an hourly sample period to get good energy estimation.

- In case of data filtered respecting Shannon (for i.e. using a Butterworth filter), wind energy estimated decreases when the vesting period of the wind increases.

- With filtered data, for sampling intervals between one minute and thirty minutes, the energy decreases linearly. This result may be interesting in wind energy prediction. To finish, these results allow better design of wind or hybrid systems, minimizing measurement equipments.

\section{ACKNOWLEDGEMENT}

The authors would like to thank Region Poitou-Charentes (Convention de recherche «GERENER » $N^{\circ}$ 08/RPC-R003) and Conseil Général Charente Maritime for their financials support.

\section{REFERENCES}

[1] Marco Ortiz, Juan Rios and Manuel Acosta,"Wind Generation and Power System Interaction Analysis using Probabilistic Techniques", in press.

[2] Joachim Peinke, Peter Schaumann and Stephan Barth "Wind Energy Colloquium Proceedings of the Euromech"_Springer-Verlag Berlin Heidelberg 2007, Preface,pp. 4

[3] Adan Simon-Muela, Vincent Boitier, Corinne Alonso, " Small-Power Wind Turbine's Characterization Application in A Production's forecast", LAAS, CNRS, in Press.

[4] Barney L.Capehart,"Encyclopedia of Energy Engineering and Technology", University of Florida Gainesville, USA, 2007 by Taylor \& Francis Group , pp. 1607 (Wind Power, K. E. Ohrn Cypress Digital Ltd., Vancouver, British Columbia, Canada).

[5] R.M.R. Kainkwa, "Wind speed pattern and the available wind power at Basotu”, Tanzania,Renewable Energy 21(2000) 289-295

[6] Paul Gipe, "Wind Power: Energy for home, Farm, and Business", 2004, reference

[7] Luminita Barote, Ionela Negrea, “ Wind Energy Probability estimation using Weibull Distribution Function “, Research article, Fascicle of Management and technological Engineering, Volume VII (XVII), 2008.

[8] W.Shepherd and D.W Shepherd, "Energy studies", Second edition, by Imperial College press, 2003, pp.306-311

[9] Wind speed Data source: http://www.nrel.gov/midc/nwtc_m2/

[10] Ali Naci Celik, "Energy output estimation for small-scale wind power generators using Weibull-representative wind data", Journal of Wind Engineering and Industrial Aerodynamics 91 (2003) 693-707.
[11] Azami Zaharim , Ahmed Mahir Razali, Rozaimah Zainal Abidin, Kamaruzzaman Sopian, "Fitting of Statistical Distributions to Wind Speed Data in Malaysia”, European Journal of Scientific Research, 2009

[12] Sher Mohammad Nasir, "Estimation of wind Energy Potentials in Pakistan”, Thesis, University of Bacochistan Quetta, 1993,pp.87

[13] Atsu S.S. Dorvlo, "Estimating wind speed distribution", Energy Conversion and Management 43 (2002) 2311-2318.

[14] Wiley Sons, "Wind Energy Handbook", Estimation of energy capture, 2001, second edition ,pp.185

[15] Thomas Ackermann, "Wind Power in Power Systems", Royal Institute of Technology Stockholm, Sweden, 2005, reference

[16] K.F. RILEY, M.P. HOBSON and S. J. BENCE,” Mathematical Methods for Physics and Engeneering", third edition , Cambridge University Press, 2006, Numerical integration, pp.1000-1018. 